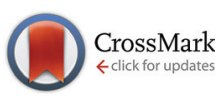

Cite this: Food Funct., 2016, 7, 1319

Received 25th January 2016,

Accepted 11th February 2016

DOI: 10.1039/c6fo00100a

www.rsc.org/foodfunction

\section{Ceratonia siliqua L. hydroethanolic extract obtained by ultrasonication: antioxidant activity, phenolic compounds profile and effects in yogurts functional- ized with their free and microencapsulated forms}

\author{
Irada Rached, ${ }^{\text {a,b,e }}$ Lillian Barros, ${ }^{\text {a,b }}$ Isabel P. Fernandes, ${ }^{b}$ Celestino Santos-Buelga, ${ }^{c}$ \\ Alírio E. Rodrigues, ${ }^{\mathrm{d}}$ Ali Ferchichi, ${ }^{\mathrm{e}}$ Maria Filomena Barreiro*b ${ }^{*}$ and \\ Isabel C. F. R. Ferreira*a
}

\begin{abstract}
Bioactive extracts were obtained from powdered carob pulp through an ultrasound extraction process and then evaluated in terms of antioxidant activity. Ten minutes of ultrasonication at $375 \mathrm{~Hz}$ were the optimal conditions leading to an extract with the highest antioxidant effects. After its chemical characterization, which revealed the preponderance of gallotannins, the extract (free and microencapsulated) was incorporated in yogurts. The microspheres were prepared using an extract/sodium alginate ratio of $100 / 400\left(\mathrm{mg} \mathrm{mg}^{-1}\right)$ selected after testing different ratios. The yogurts with the free extract exhibited higher antioxidant activity than the samples added with the encapsulated extracts, showing the preserving role of alginate as a coating material. None of the forms significantly altered the yogurt's nutritional value. This study confirmed the efficiency of microencapsulation to stabilize functional ingredients in food matrices maintaining almost the structural integrity of polyphenols extracted from carob pulp and furthermore improving the antioxidant potency of the final product.
\end{abstract}

\section{Introduction}

New functional products launched in the global food \& beverage market have followed a route of fortification (or addition) of health promoting nutrients and bioactives, including vitamins, minerals, antioxidants, omega-3 fatty acids, plant extracts, prebiotics and probiotics, and fiber. Many of those ingredients are prone to degradation and/or can interact with other components in the food matrix, leading to a progressive loss in the quality of the functional food products. ${ }^{1}$ Furthermore, other challenges are inherent to the incorporation of bioactive ingredients, such as masking any undesirable taste

\footnotetext{
${ }^{a}$ Mountain Research Centre (CIMO), ESA, Polytechnic Institute of Bragança, Campus Santa Apolónia, 1172, 5301-855 Bragança, Portugal. E-mail: iferreira@ipb.pt; Fax: +35 1-273-325405; Tel: +35 1-273-303219

${ }^{b}$ Laboratory of Separation and Reaction Engineering (LSRE), Associate Laboratory LSRE/LCM, Polytechnic Institute of Bragança, Campus Santa Apolónia, 1134, 5301-857 Bragança, Portugal. E-mail: barreiro@ipb.pt; Fax: +35 1273325405; Tel: +35 1273303089

${ }^{c}$ GIP-USAL, Facultad de Farmacia, Universidad de Salamanca, Campus Miguel de Unamuno, 37007 Salamanca, Spain

${ }^{d}$ Laboratory of Separation and Reaction Engineering (LSRE), Associate Laboratory LSRE/LCM, Faculty of Engineering, University of Porto, Porto, Portugal

${ }^{e}$ Rural Laboratory, National Institute of Agronomic of Tunisia, 43, Charles Nicolle, 1082, Tunis, Mahrajene, Tunisia
}

and odor, thus maintaining the overall sensory quality of the final food product. ${ }^{2}$ In this context, microencapsulation has been employed as a technology able to minimize, if not solve, these challenges, offering additionally the possibility to develop tailor-made ingredients for specific applications. Opportunities for the use of microencapsulation in the food industry sector continue to grow as greater demands are required to control the release and delivery of the core material through the capsule at a specific time during digestion and to a specified site in the body. ${ }^{3,4}$

Popularly known as St John's Bread, Ceratonia siliqua L. (carob) has a long history of use in the human diet (over 4000 years). ${ }^{5,6}$ For many centuries, carob pods have been used in many countries for both human and animal nutrition. In modern society, carob pods are ground into a nutritious powder which is incorporated as an ingredient in a variety of food products such as confectioneries, beverages, sweet bars and ice creams. ${ }^{5,7,8}$ Indeed, carob has a good nutritional value and it is relatively cheap. Due to its high sugar content (60\% sugar, mainly sucrose), carob is naturally sweet. It has also a nutty chocolate-like flavor, but unlike chocolate or cocoa, carob does not contain any caffeine, theobromine or oxalic acid. In addition carob is normally regarded as a healthy food because of its low fat content $(0.2-2.3 \%)$ as well the presence of some minerals such as calcium, phosphorous and potassium. ${ }^{9,10}$ 
The health promoting effects of carob pulp have been related mainly to its polyphenolic content (up to 20\%) and to the presence of dietary fibers (as high as 39.8\%). ${ }^{9,11-13}$ Unfortunately, these valuable natural compounds' uses are substantially limited. The instability during food processing, distribution or storage, or in the gastrointestinal tract $(\mathrm{pH}$, enzymes, presence of other nutrients), limits the bioactivity and thus the potential health benefits of polyphenols. Furthermore, they oxidize very quickly, leading to the progressive appearance of a brown color and/or unwanted odors with a considerable loss in activity. ${ }^{14}$

The present study aimed at obtaining phenolic extracts of C. siliqua (kibbles powder) by using ultrasound assisted extraction with an ethanol : water mixture $(80: 20, \mathrm{v} / \mathrm{v})$, and test their use as an antioxidants source in functional yogurts. Due to the stability problems mentioned above, microencapsulation was applied to the extracts, being the performance of the free and protected forms evaluated and compared.

\section{Materials and methods}

\subsection{Samples}

Fresh pods of Ceratonia siliqua L. were collected from carob trees cultivated in the region of Sousse (Tunisia). The population belongs to bioclimatic coefficient according to pluviothermic Emberger scale. ${ }^{15}$ The pods were collected during the period from July to September 2014. Carob kibbles (chopped and deseeded carob pods) were lyophilized and then stored in cans in dry atmosphere at room temperature and dark conditions.

\subsection{Standards and reagents}

2,2-Dipheny-1-picrylhydrazyl (DPPH) was obtained from Alfa Aesar (Ward Hill, MA, USA). HPLC-grade acetonitrile was from Fisher Scientific (Lisbon, Portugal). The fatty acids methyl ester (FAME) reference standard mixture (standard 47885-U), $\beta$-carotene and trolox (6-hydroxy-2,5,7,8-tetramethylchroman-2carboxylic acid) were purchased from Sigma (St Louis, MO, USA), as also formic acid. Phenolic compound standards, namely gallic acid, ellagic acid, quercetin-3-O-glucoside and naringenin, were purchased from Extrasynthèse (Genay, France). Sodium alginate was provided from Fluka Chemie (Steinheim, Switzerland). All other chemicals and solvents were of analytical grade and purchased from common sources. Water was treated in a Milli-Q water purification system (TGI Pure Water Systems, Greenville, SC, USA).

\subsection{Ultrasound assisted extraction}

The samples of carob kibbles ( $3 \mathrm{~g}$ ) were extracted with a mixture of ethanol/water $(80: 20, \mathrm{v} / \mathrm{v})(100 \mathrm{~mL})$ along three different times $(5,10$ and $15 \mathrm{~min})$ and using three different ultrasound powers (250, 375 and $500 \mathrm{~W}$ ), in independent experiments. An ultrasonic device QSonica sonicator, model CL-334 (Newtown, CT, USA) was used. The extracts were then filtered through a Whatman paper filter no. 4, concentrated under vacuum to remove ethanol, and lyophilized (FreeZone 4.5., Labconco, Kansas City, MO, USA) to remove the water.

\subsection{Evaluation of the antioxidant activity}

2.4.1 General. For each sample, five solutions with different concentrations were prepared by dilution from a stock solution. This latter was obtained by dissolving $100 \mathrm{mg}$ of each ultrasound extract in $10 \mathrm{~mL}$ of solvent (ethanol : water $80: 20, \mathrm{v} / \mathrm{v})$. The concentrations tested were: 10, 5, 2.5, 1.25, $0.625,0.312$ and $0.156 \mathrm{mg} \mathrm{mL}^{-1}$. Trolox was used as the positive control.

2.4.2. DPPH radical-scavenging activity. This assay was performed using an ELX800 Microplate Reader (Bio-Tek Instruments, Inc., Winooski, VT, USA), according to the procedure described by Martins et al. ${ }^{16}$ The reaction mixture in each one of the 96 wells comprised one of the different extract concentrations prepared $(30 \mu \mathrm{L})$ and an aqueous methanolic solution $(80: 20 \mathrm{v} / \mathrm{v}, 270 \mu \mathrm{L})$ containing DPPH radicals $\left(6 \times 10^{-5} \mathrm{~mol} \mathrm{~L}^{-1}\right)$. The mixture was left to stand for $60 \mathrm{~min}$ in the dark. The reduction of the DPPH radical was determined by measuring the absorbance at $515 \mathrm{~nm}$. The radical-scavenging activity (RSA) was calculated as a percentage of DPPH discoloration using the equation: \%RSA $=\left[\left(A_{\mathrm{DPPH}}-A_{\mathrm{S}}\right) / A_{\mathrm{DPPH}}\right] \times 100$, where $A_{\mathrm{S}}$ is the absorbance of the solution when the sample extract has been added at a particular level, and $A_{\mathrm{DPPH}}$ is the absorbance of the DPPH solution. The extract concentration providing $50 \%$ of the radical scavenging activity $\left(\mathrm{EC}_{50}\right)$ was calculated from the graph of RSA percentage against extract concentration.

2.4.3. Reducing power. The various extract solutions (0.5 mL) were mixed with sodium phosphate buffer (200 mmol L $\mathrm{m}^{-1}$, pH 6.6, $0.5 \mathrm{~mL}$ ) and potassium ferricyanide $(1 \% \mathrm{w} / \mathrm{v}, 0.5 \mathrm{~mL})$. The mixture was incubated at $50{ }^{\circ} \mathrm{C}$ for $20 \mathrm{~min}$, followed by trichloroacetic acid $(10 \% \mathrm{w} / \mathrm{v}, 0.5 \mathrm{~mL})$ addition. The mixture $(0.8 \mathrm{~mL})$ was poured into the 48 wells, along with deionized water $(0.8 \mathrm{~mL})$ and ferric chloride $(0.1 \%$ $\mathrm{w} / \mathrm{v}, 0.16 \mathrm{~mL}$ ), and the absorbance was measured at $690 \mathrm{~nm}$ in the microplate reader described above. ${ }^{16}$ The extract concentration providing 0.5 of absorbance $\left(\mathrm{EC}_{50}\right)$ was calculated from the graph of absorbance at $690 \mathrm{~nm}$ against extract concentration.

2.4.4. Inhibition of $\boldsymbol{\beta}$-carotene bleaching. The evaluation of $\beta$-carotene bleaching inhibition is based on the non-specific oxidation of linoleic acid, catalyzed by heat $\left(50^{\circ} \mathrm{C}\right)$, following a procedure previously described. ${ }^{16}$ The addition of an extract containing antioxidants promotes a decolouration delay of $\beta$-carotene by the inhibition of the oxidation of linoleic acid. Two milliliters of $\beta$-carotene solution $\left(0.2 \mathrm{mg} \mathrm{mL}^{-1}, \mathrm{w}: \mathrm{v}\right.$ in chloroform) were transferred into a round-bottom flask and chloroform removed at $40{ }^{\circ} \mathrm{C}$ under vacuum. Linoleic acid (40 mg), Tween 80 emulsifier (400 mg), and distilled water $(100 \mathrm{~mL})$ were added to the flask with vigorous shaking. Aliquots $(4.8 \mathrm{~mL})$ of this emulsion were transferred into test tubes containing different concentrations of the extracts $(0.2 \mathrm{~mL})$ and zero time absorbance was measured at $470 \mathrm{~nm}$ (Analytik Jena 200 spectrophotometer, Jena, Germany). Then, tubes were incubated at $50{ }^{\circ} \mathrm{C}$ in a shaking water bath. $\beta$-Caro- 
tene bleaching inhibition was calculated using the following equation:

$\beta$-Carotene bleaching inhibition ratio (\%)

$=$ absorbance after $2 \mathrm{~h}$ of assay/initial absorbance $\times 100$.

The extract concentration providing $50 \%$ of antioxidant activity $\left(\mathrm{EC}_{50}\right)$ was calculated from the graph of $\beta$-carotene bleaching inhibition against extract concentration.

2.4.5. Thiobarbituric acid reactive substances (TBARS) assay. A solution of porcine cerebral tissue homogenate was obtained according to the procedure reported by Martins et $a{ }^{16}{ }^{16}$ An aliquot $(0.1 \mathrm{~mL})$ was incubated with the extracts at different concentrations $(0.2 \mathrm{~mL})$ in the presence of $\mathrm{FeSO}_{4}$ $(10 \mu \mathrm{M} ; 0.1 \mathrm{~mL})$ and ascorbic acid $(0.1 \mathrm{mM} ; 0.1 \mathrm{~mL})$ at $37{ }^{\circ} \mathrm{C}$ for $1 \mathrm{~h}$. The reaction was stopped by the addition of trichloroacetic acid $(28 \% \mathrm{w} / \mathrm{v}, 0.5 \mathrm{~mL})$, followed by thiobarbituric acid (TBA, 2\% w/v, $0.38 \mathrm{~mL}$ ), and the mixture was then heated at $80{ }^{\circ} \mathrm{C}$ for $20 \mathrm{~min}$. After centrifugation at $3000 \mathrm{~g}$ for $10 \mathrm{~min}$, the color intensity of the malondialdehyde (MDA)-TBA complex in the supernatant was measured by its absorbance at $532 \mathrm{~nm}$. The inhibition ratio (\%) was calculated using the following formula, where $A$ and $B$ were the absorbance of the control and the extract solution, respectively: TBARS inhibition ratio $(\%)=[(A \times B) /(A)] \times 100$. The extract concentration providing $50 \%$ of lipid peroxidation inhibition $\left(\mathrm{EC}_{50}\right)$ was calculated from the graph of TBARS inhibition percentage against extract concentration.

2.4.6. Total phenolics and flavonoids content. Total phenolics were determined for all of the obtained extracts by using the Folin-Ciocalteu colorimetric method. ${ }^{17}$ Briefly, the extract sample (or water for blank) $(500 \mu \mathrm{L})$ was mixed with $1 / 10(\mathrm{v} / \mathrm{v})$ diluted Folin-Ciocalteu reagent $(2.5 \mathrm{~mL})$ and $7.5 \%$ $\mathrm{Na}_{2} \mathrm{CO}_{3}(2 \mathrm{~mL})$. Absorbance was measured at $765 \mathrm{~nm}$ after vortex mixing during $15 \mathrm{~s}$ and incubation at $40{ }^{\circ} \mathrm{C}$ for $30 \mathrm{~min}$. Total phenolics were expressed as mg GAE (gallic acid equivalents) per $\mathrm{mL}$ by comparison a gallic acid standard curve (0.05-0.8 $\mathrm{mM}$ ) and converted to $\mathrm{mg}$ GAE per $\mathrm{g}$ dry extract.

Flavonoids content was determined using the method of Jia et al. ${ }^{18}$ with some modifications. An aliquot $(0.5 \mathrm{~mL})$ of the extract solution was mixed with distilled water $(2 \mathrm{~mL})$ and subsequently with a $\mathrm{NaNO}_{2}$ solution $(5 \%, 0.15 \mathrm{~mL})$. After $6 \mathrm{~min}$, $\mathrm{AlCl}_{3}$ solution $(10 \%, 0.15 \mathrm{~mL})$ was added and allowed to stand for a further $6 \mathrm{~min}$; thereafter, a $\mathrm{NaOH}$ solution $(4 \%, 2 \mathrm{~mL})$ was added to the mixture. Immediately, distilled water was added to bring a final volume to $5 \mathrm{~mL}$. Then, the mixture was properly homogeneized and allowed to stand for $15 \mathrm{~min}$. The intensity of pink color was measured at $510 \mathrm{~nm}$. (+)-Catechin was used to calculate the standard curve $(0.0156-1.0 \mathrm{mM})$ and the results were expressed as $\mathrm{mg}$ of $(+)$-catequin equivalents (CE) per $g$ of extract.

\subsection{Analysis of phenolic compounds}

The best extract in terms of antioxidant activity was analysed, after dissolution of $500 \mathrm{mg}$ in $5 \mathrm{~mL}$ of ethanol/water $(20: 80, \mathrm{v} / \mathrm{v})$, using a Hewlett-Packard 1100 chromatograph (Agilent
Technologies) with a quaternary pump and a diode array detector (DAD) coupled to an HP Chem Station (rev. A.05.04) dataprocessing station. A Waters Spherisorb S3 ODS-2 $\mathrm{C}_{18},(3 \mu \mathrm{m}$, $4.6 \times 150 \mathrm{~mm}$ ) column thermostatted at $35^{\circ} \mathrm{C}$ was used. The used solvents were: (A) $0.1 \%$ aqueous acid formic acid, (B) acetonitrile. The elution gradient established was $15 \% \mathrm{~B}$ for $5 \mathrm{~min}, 15 \%$ B to $20 \%$ B over $5 \mathrm{~min}, 20-25 \%$ B over $10 \mathrm{~min}$, 25-35\% B over $10 \mathrm{~min}, 35-50 \%$ for $10 \mathrm{~min}$, and re-equilibration of the column, using a flow rate of $0.5 \mathrm{~mL} \mathrm{~min}^{-1}$. Double online detection was carried out with DAD using $280 \mathrm{~nm}$ and $370 \mathrm{~nm}$ as preferred wavelengths and a mass spectrometer (MS) coupled to the HPLC system via the DAD cell outlet.

MS detection was performed in an API 3200 Qtrap (Applied Biosystems, Darmstadt, Germany) equipped with an ESI source and a triple quadrupole-ion trap mass analyser controlled by the software Analyst 5.1. Zero grade air served as the nebulizer gas (30 psi) and turbo gas for solvent drying $\left(400{ }^{\circ} \mathrm{C}\right.$, 40 psi). Nitrogen served as the curtain (20 psi) and collision gas (medium). The quadrupole was set at unit resolution. The ion spray voltage was set at $-4500 \mathrm{~V}$ in the negative mode. The MS detector was programmed for recording in two consecutive modes: Enhanced MS (EMS) and enhanced product ion (EPI) analysis. EMS was employed to show full scan spectra, so as to obtain an overview of all of the ions in sample. Settings used were: declustering potential (DP) $-450 \mathrm{~V}$, entrance potential (EP) $-6 \mathrm{~V}$, collision energy (CE) $-10 \mathrm{~V}$. EPI mode was performed in order to obtain the fragmentation pattern of the parent ion(s) in the previous scan using the following parameters: DP $-50 \mathrm{~V}, \mathrm{EP}-6 \mathrm{~V}, \mathrm{CE}-25 \mathrm{~V}$, and collision energy spread (CES) $0 \mathrm{~V}$. Spectra were recorded in negative ion mode between $\mathrm{m} / \mathrm{z} 100$ and 1700 .

The phenolic compounds were characterized according to their UV and mass spectra and retention times compared with standards when available. For the quantitative analysis, a 5-level calibration curve was obtained by injection of known concentrations $\left(2.5-100 \mu \mathrm{g} \mathrm{mL}{ }^{-1}\right)$ of different standard compounds: gallic acid $\left(y=365.2 x-38.923 ; R^{2}=0.9999\right)$; ellagic acid ( $\left.y=38.466 x+35.44 ; R^{2}=0.9994\right)$; quercetin 3-O-glucoside $\left(y=336.36 x+358.06 ; R^{2}=0.9984\right) ;$ naringenin $(y=539.98 x+$ $\left.161.46 ; R^{2}=0.9939\right)$. The results were expressed in $\mathrm{mg}$ per $\mathrm{g}$ of extract.

\subsection{Microencapsulation of the extract}

2.6.1. Microsphere's preparation. Microspheres containing the extract were prepared by an atomization/coagulation technique, using different extract/sodium alginate ratios (50/400, $75 / 400$ and $100 / 400, \mathrm{mg} \mathrm{mg}^{-1}$ ) in order to choose the most suitable one. Briefly, sodium alginate was used as the matrix material and $\mathrm{CaCl}_{2}$ aqueous solution as the coagulation agent. The extract solution was prepared by dissolving the lyophilized hydroalcoholic extract in $10 \mathrm{~mL}$ of distilled water under stirring. Then, $400 \mathrm{mg}$ of sodium alginate was added to this solution. This latter was kept under stirring until complete alginate dissolution was achieved. Thereafter, the alginate solution containing the extract was atomized using a NISCO 
Var J30 system (feed rate of $0.3 \mathrm{~mL} \mathrm{~min}^{-1}$ and a nitrogen pressure of 0.1 bar) to produce the microspheres. The atomized microspheres were coagulated by contacting with a $\mathrm{CaCl}_{2}$ aqueous solution $(250 \mathrm{~mL}$ at a concentration of $4 \%$ $(\mathrm{w} / \mathrm{v})$ ), for 4 hours. The resulting microspheres were collected by filtration under reduced pressure and washed twice with distilled water. The obtained microspheres were then lyophilized and stored under dark conditions at $4{ }^{\circ} \mathrm{C}$.

2.6.2. Microsphere's characterization. The obtained microspheres were characterized by optical microscopy (OM) using a Nikon Eclipse 50i microscope equipped with a Nikon Digital Sight camera and NIS Elements software for data acquisition. $\mathrm{OM}$ analysis was applied to access the size and morphology of the microspheres after the production and coagulation stages, respectively. It was also possible to infer the presence/absence of extract inside the microspheres. The encapsulation efficiency (EE) was evaluated by HPLC-DAD in terms of the most abundant phenolic acid and flavonoid compounds present in the extract: tetragalloyl-glucose (quantified as gallic acid equivalents) and quercetin-3-O-glucoside, respectively. For this quantification the non-encapsulated compounds were determined by analysing the coagulation bath and the washing solutions following the methodology described by Martins et $a l .{ }^{16}$

\subsection{Yogurts with incorporated free and microencapsulated extracts}

2.7.1. Incorporation procedure. The chosen food matrix was a natural yogurt without added sugar and 5\% (w/w) of fat. Yogurt was mixed in order to ensure sample homogeneity before assays preparation and then distributed in pots (125 $\mathrm{g}$ each). Six samples were prepared: two samples of pure yogurt (125 $\mathrm{g}$ each, used as the control sample), two samples of yogurt (125 g each) incorporated with free extract $(370 \mathrm{mg}$ of lyophilized powder of the $C$. siliqua hydroalcoholic extract) and two samples of yogurt (125 g each) incorporated with microencapsulated extract (609 $\mathrm{mg}$ of lyophilized microspheres). The samples were prepared taking into consideration the use of microcapsules produced with an extract/ sodium alginate ratio of $100 / 400, \mathrm{mg} \mathrm{mg}^{-1}$. The used amount of microcapsules incorporates an equivalent amount of the used free extract.

2.7.2. Antioxidant activity. The antioxidant activity was evaluated at two different sampling times, namely: at initial time $(t=0)$, i.e. immediately after the addition of free or microencapsulated extracts, and after 3 days $(t=3)$. The collected samples at $t=0$ and $t=3$ were lyophilized and conditioned for future analysis. The antioxidant activity was evaluated by determining the DPPH radical scavenging activity and reducing power, as described in the previous sections.

2.7.3. Nutritional composition. The samples were also analyzed for proximate composition (moisture, protein, fat, carbohydrates and ash). ${ }^{19}$ The crude protein content $(N \times 6.38)$ of the samples was estimated by Kjeldahl method; the crude fat was determined by extracting a known weight of powdered sample with petroleum ether, using a Soxhlet apparatus; the ash content was determined by incineration at $600 \pm 15{ }^{\circ} \mathrm{C}$. Total carbohydrates were calculated by difference: $[100-$ $(\mathrm{g}$ moisture $+\mathrm{g}$ protein $+\mathrm{g}$ lipid $)]$. Total energy was calculated according to the following equation:

Energy $($ kcal $)=4 \times($ g protein $+\mathrm{g}$ carbohydrate $)+9 \times(\mathrm{g}$ lipid $)$.

\subsection{Statistical analysis}

The extractions were performed in triplicate and all the assays were also carried out in triplicate. The results were expressed as mean values with the corresponding standard deviation (SD). The results were analyzed using the one-way analysis of variance (ANOVA) followed by Tukey's HSD test with $\alpha=0.05$. In the case of antioxidant activity and nutritional value of the yogurts, a Student's $t$-test was used to determine the significant difference among the different samples $(\alpha=0.05)$. This treatment was carried out using SPSS v. 22.0 program.

\section{Results and discussion}

\subsection{Extraction yields and in vitro antioxidant properties of the hydroalcoholic extracts}

The yields for the extractions performed at different ultrasound power and time are shown in Table 1 . The extractions performed at $375 \mathrm{~W}$ (for all the times) and at $500 \mathrm{~W}$ for 15 min led to the highest extraction yields, without significant statistical differences.

In this study the extraction solvent, an important parameter of the extraction process, was chosen according to Dimitrov et $a .^{20}$ that reported ethanol: water mixtures as more suitable for the ultrasound extraction of phenolic compounds from carob pod in comparison with pure water.

Concerning the antioxidant activity, the best performance (lowest $\mathrm{EC}_{50}$ values) was observed for the hydroethanolic extracts obtained at 375 and $500 \mathrm{~W}$ during 10 minutes, without significant statistical differences, which was in agreement with the greater phenolic and flavonoid contents found in those extracts (Table 1). The obtained values were in accordance with the ones reported by Rakib et $a{ }^{11}{ }^{11}$ in Carob pods grown in different regions of Morocco, but were higher than those described by Ayaz et $a .^{21}$ and Makris and Kefalas ${ }^{9}$ for Carob from Turkey and Crete, respectively.

Considering that $375 \mathrm{~W}$ will involve less energy than $500 \mathrm{~W}$, this power with $10 \mathrm{~min}$ of extraction was considered the most suitable to obtain the hydroethanolic extract. Therefore, this extract was used in the subsequent stages of the study.

\subsection{Phenolic profile of the best antioxidant extract}

Nineteen phenolic compounds were identified in the hydroalcoholic extract obtained by ultrasonication of carob pulp powder using $375 \mathrm{~W}$ during 10 minutes (Fig. 1). The characteristics of the compounds and corresponding tentative identities are presented in Table 2. The main phenolic compounds present were gallotannins (galloyl, digalloyl, trigalloyl, tetragalloyl and pentagalloyl glucose) followed by flavonoids (narin- 


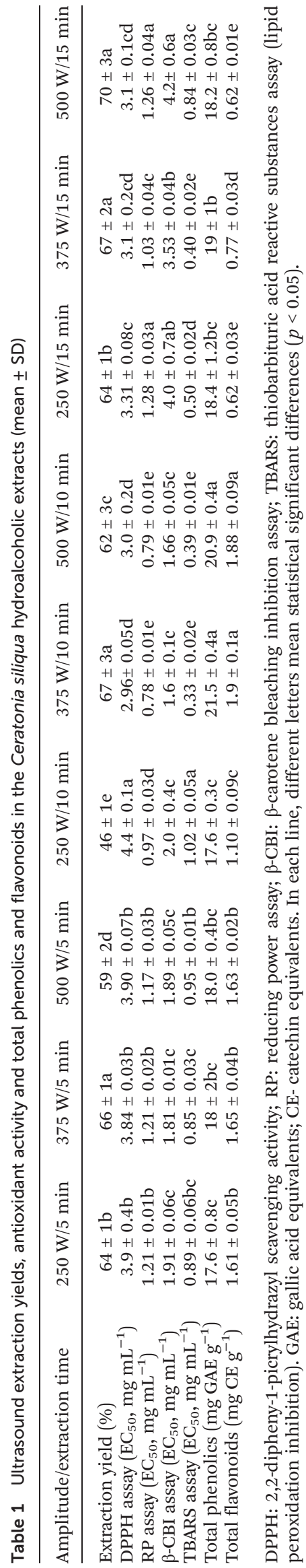

genin, myricetin, quercetin and kaempferol derivatives). Ellagic acid was the only detected phenolic acid and positively identified according to its retention, mass and UV-vis characteristics by comparison with a commercial standard. This compound has been previously identified in carob pods grown in different regions of Morocco. ${ }^{11}$ Recent reports has associated this acid with both protecting normal cells from induced oxidative damage and apoptosis ${ }^{22}$ as well as down-regulation of inflammatory-associated molecules in different cell systems. ${ }^{23}$ Ellagic acid has also been shown to protect against doxorubicininduced cardiac injury in mice, ${ }^{24}$ methotrexate-induced small intestine damage in rats $^{25}$ and cyclophosphamide-induced renal injury, DNA-damage and genotoxicity in Swiss albino mice. $^{26}$

Compounds 1-8, 10-12 and $\mathbf{1 7}$ were identified as gallotannins composed by monomeric, dimeric, trimeric, tetrameric and pentameric galloyl moieties linked to a glucose. According to the literature, ${ }^{27}$ the main characteristics in the mass spectra of these compounds are the deprotonated molecule $[\mathrm{M}-\mathrm{H}]^{-}(\mathrm{m} / \mathrm{z} 483,635,787$ and 939) and the loss of one or more galloyl groups (152 mass units) and/or gallic acid (170 mass units). Compounds 1 and $4\left([\mathrm{M}-\mathrm{H}]^{-}\right.$ion at $\mathrm{m} / \mathrm{z}$ 483) revealed a typical fragmentation pattern of a digalloyl glucose, while compounds $3,5,7$ and $8\left([\mathrm{M}-\mathrm{H}]^{-}\right.$ion at $\mathrm{m} / \mathrm{z}$ 635), compounds 10-12 ([M- H $]^{-}$ion at $\left.m / z 787\right)$ and compound $17\left([\mathrm{M}-\mathrm{H}]^{-}\right.$ion at $m / z$ 939) presented a fragmentation pattern characteristic of trigalloyl, tetragalloyl and pentagalloyl glucose, respectively. ${ }^{27}$ Similar compounds have been previously reported in carob pods and derived products. ${ }^{6,11,28}$ Compounds $2\left([\mathrm{M}-\mathrm{H}]^{-}\right.$ ion at $m / z 443)$ and $6\left([\mathrm{M}-\mathrm{H}]^{-}\right.$ion at $\left.m / z 595\right)$ possessed pseudomolecular ions $112 \mathrm{u}$ greater than galloyl-glucose $(\mathrm{m} / \mathrm{z} 331)$ and digalloyl-glucose $(\mathrm{m} / \mathrm{z}$ 483), respectively, and a fragmentation pattern similar to those gallotannins. No identity could be matched for the unknown residue, so that they were just tentatively assigned as galloyl-glucose and digalloyl-glucose derivatives.

Gallotannins were the main phenolic compounds present in the C. siliqua extract, being compounds $\mathbf{1 0}$ and $\mathbf{5}$, a tetraand a trigalloyl-glucose, respectively, the majority molecules found. This group of phenolics has been reported to display several important biological and pharmacological activities, such as virustatic, ${ }^{29}$ anti-oxidant and free radical scavenging, ${ }^{30}$ anti-inflammatory, ${ }^{31}$ anti-diabetic, ${ }^{32}$ antitumor, ${ }^{33}$ and enzyme inhibition, ${ }^{34}$ and keratinocyte proliferation and mitochondrial stimulating, ${ }^{35}$ activities.

The remaining compounds were identified as flavonoids. Compounds $9\left([\mathrm{M}-\mathrm{H}]^{-}\right.$at $\left.\mathrm{m} / \mathrm{z} 479\right)$ and $14\left([\mathrm{M}-\mathrm{H}]^{-}\right.$at $\mathrm{m} / \mathrm{z}$ 463) were assigned as myricetin- $O$-hexoside and myricetin- $O$ pentoside, respectively, taking into account its mass spectra and maximal wavelength ( $\lambda_{\max }$ at $352 \mathrm{~nm}$ ), but also its previous identification in carob samples. ${ }^{11,13,28}$ A multitude of studies have been performed using the beneficial properties of myricetin in cultured cells and diabetic animals. Based on recent results, it was clear that myricetin has a powerful effect at cellular level being promising as a novel approach for the prevention and management of Diabetes Mellitus and its complications. $^{36}$ 

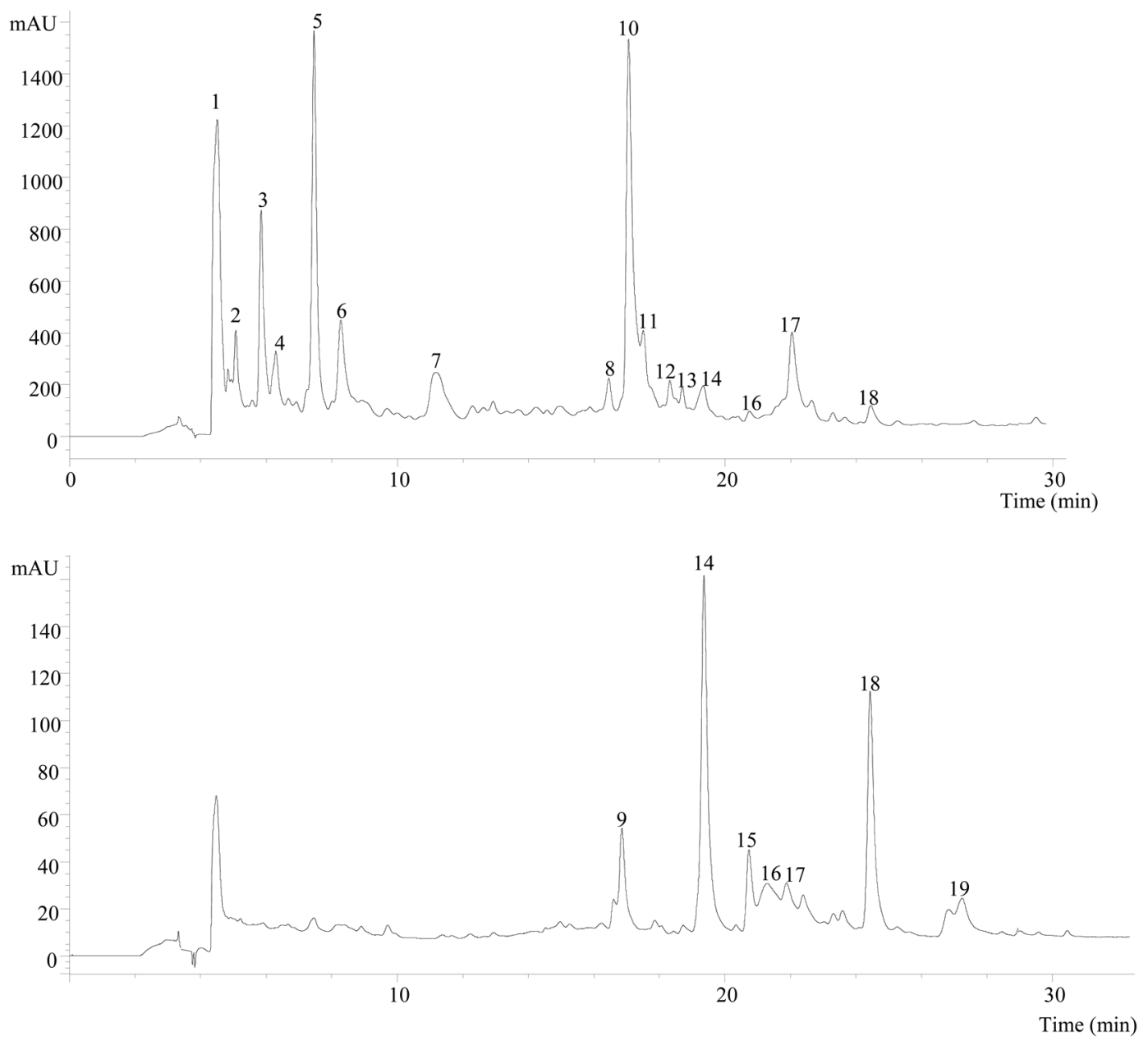

Fig. 1 HPLC phenolic profile of Ceratonia siliqua hydroethanolic extract, obtained at $280 \mathrm{~nm}$ (A) and $370 \mathrm{~nm}$ (B).

Compound $15\left([\mathrm{M}-\mathrm{H}]^{-}\right.$at $\left.m / z 463\right)$ was positively identified as quercetin-3-O-glucoside by comparison with a commercial standard. The pseudomolecular ion of peak $18\left([\mathrm{M}-\mathrm{H}]^{-}\right.$ at $m / z 447$ ) was coherent with a quercetin- $O$-deoxyhexoside and was tentatively assigned to quercetin-3-O-rhamnoside owing to its previous identification by NMR in C. siliqua. ${ }^{37}$ Compounds $19\left([\mathrm{M}-\mathrm{H}]^{-}\right.$at $\left.m / z 461\right)$ and $13\left([\mathrm{M}-\mathrm{H}]^{-}\right.$at $\mathrm{m} / z$ 433) were tentatively identified as kaemferide- $O$-hexoside and naringenin-O-hexoside, respectively. Quercetin, narigenin and kaemferide glycosides have been previously reported in carob samples. ${ }^{6,11,13,28,38}$ These flavonoids, especially quercetin and narigenin, exert effects by controlling the mechanisms of ROS production, which might be seen as a positive effect when considering the importance of antioxidant agents in oxidative stress conditions or a negative effect when considering the importance of ROS for microbicidal activity. ${ }^{39}$

In comparison with others studies, our data show differences in terms of the identified phenolic compounds and respective quantification. Papagiannopoulos et al. ${ }^{28}$ identified 41 individual phenolic compounds in carob pods from Germany and presented gallic acid and myricetin-desoxyhexo- side as the main molecules. Rakib et $a .^{11}$ studied six samples of carob pods from different regions of Morocco and revealed the presence of 52 phenolic compounds in their ethanolic extracts, in which the major compounds were gallic acid, gallate glucoside and gallic acid glucoside, depending on the sample. Nevertheless, these samples did not present many gallotannins derivatives. Torun et al. ${ }^{40}$ described the phenolic profile for natural carob-pod flour, being phenolic acids the main identified molecules, in particular gallic acid. Ayaz et $a .^{21}$ also presented the phenolic acid fraction of carob pods in which gallic acid was also the main compound. Roseiro et $a{ }^{13}{ }^{13}$ studied carob pulp kibbles, a by-product of the carob bean gum production, revealing the presence of six phenolic acids and eleven flavonoids, being ferulic acid and chrysoeriol the major compounds identified.

\subsection{Production of alginate microspheres containing the hydroalcoholic extract}

The evaluation of the obtained microspheres by OM, during different stages of the encapsulation process, and after being lyophilised for storage purposes, revealed changes in their 
Table 2 Retention time (Rt), wavelengths of maximum absorption in the visible region $\left(\lambda_{\max }\right)$, mass spectral data and identification of phenolic compounds in the hydroethanolic extract of Ceratonia siliqua (mean \pm SD)

\begin{tabular}{|c|c|c|c|c|c|c|}
\hline Compound & $\begin{array}{l}\mathrm{Rt} \\
(\mathrm{min})\end{array}$ & $\begin{array}{l}\lambda_{\max } \\
(\mathrm{nm})\end{array}$ & $\begin{array}{l}\text { Molecular ion } \\
{[\mathrm{M}-\mathrm{H}]^{-}(\mathrm{m} / \mathrm{z})}\end{array}$ & $\operatorname{MS}^{2}(m / z)$ & $\begin{array}{l}\text { Tentative } \\
\text { identification }\end{array}$ & $\begin{array}{l}\text { Quantification } \\
{\text { (mg } \mathrm{g}^{-1} \text { extract }}\end{array}$ \\
\hline 1 & 4.5 & 276 & 483 & 331(52), 313(38), 271(4), 211(5), 169(90) & Digalloyl-glucose & $6.82 \pm 0.01$ \\
\hline 3 & 5.8 & 278 & 635 & $\begin{array}{l}483(40), 465(7), 423(3), 331(15), 271(6), \\
211(6), 169(16)\end{array}$ & Trigalloyl-glucose & $5.01 \pm 0.04$ \\
\hline 4 & 6.3 & 276 & 483 & $331(14), 313(31), 271(74), 211(15), 169(27)$ & Digalloyl-glucose & $1.9 \pm 0.1$ \\
\hline 5 & 7.5 & 276 & 635 & $\begin{array}{l}\text { 483(17), 465(100), 423(12), 331(9), 313(37), } \\
271(3), 169(38)\end{array}$ & Trigalloyl-glucose & $9.5 \pm 0.1$ \\
\hline 7 & 11.2 & 278 & 635 & $\begin{array}{l}\text { 483(33), 465(93), 423(3), 313(41), 271(5), } \\
211(8), 169(29)\end{array}$ & Trigalloyl-glucose & $4.27 \pm 0.04$ \\
\hline 8 & 16.4 & 276 & 635 & 483(23), 465(46), 313(25), 169(23) & Trigalloyl-glucose & $1.89 \pm 0.05$ \\
\hline 9 & 16.9 & 352 & 479 & $317(100)$ & Myricetin- $O$-hexoside & $0.27 \pm 0.02$ \\
\hline 10 & 17.1 & 278 & 787 & 635(18), 617(77), 465(30), 447(6), 313(4), 169(16) & Tetragalloyl-glucose & $12.59 \pm 0.01$ \\
\hline 11 & 17.5 & 278 & 787 & 635(23), 617(53), 465(20), 447(5), 313(3), 169(7) & Tetragalloyl-glucose & $3.2 \pm 0.2$ \\
\hline 17 & 22.0 & 278 & 939 & 787(100), 635(4), 617(11), 465(4) & Pentagalloyl-glucose & $3.7 \pm 0.2$ \\
\hline 18 & 24.4 & 350 & 447 & $301(100)$ & Quercetin-3-O-rhamnoside & $0.82 \pm 0.01$ \\
\hline \multirow[t]{5}{*}{19} & 26.8 & 352 & 461 & $299(25), 284(50)$ & Kampferide- $O$-hexoside & $0.025 \pm 0.001$ \\
\hline & & & & & Total gallotannins & $56.6 \pm 0.6$ \\
\hline & & & & & Total phenolic acids & $1.20 \pm 0.01$ \\
\hline & & & & & Total flavonoids & $3.14 \pm 0.05$ \\
\hline & & & & & Total phenolic compounds & $60.9 \pm 0.6$ \\
\hline
\end{tabular}

shape. In fact, at the end of the atomisation step (Fig. 2A, D and $\mathrm{G}$ ) and coagulation processes (Fig. 2B, E and H), microspheres with various dimensions and a clear spherical form were observed. These dispersions contain a microcapsules' population without any ruptures or pores on the surface and with a minimal presence of notches, thus compatible with a high degree of integrity. ${ }^{41}$ After being dried (Fig. 2C, $\mathrm{F}$ and I), the microspheres corresponding to the different ratios applied showed a ruffled form being apparently glued to each other possibly due to the absence of water. Another observation was the presence of a growing number of small microcapsules as the ratio extract/alginate increases. Overall, their estimated size at all the different ratios used and during the different stages was comprised between $129 \mu \mathrm{m}$ and $360 \mu \mathrm{m}$. The HPLC-DAD analysis of the coagulation and the washing solutions, which revealed to present none or only traces of the extract, let to estimate an EE around $100 \%$ for all the tested extract/alginate ratios. In fact, the use of a large amount of extract did not compromise the achieved EE.

Taking into account the amount of microcapsules to be incorporated in the food matrix and following various tests for the production of microcapsules, the ratio chosen among the three tested ones was 100/400. In fact, twelve tests of atomization/coagulation using this ratio produced the total amount of microcapsules to be incorporated (compared to 17 trials for the ratio 50/400 and 20 for the ratio 75/400).

The extract chosen for the microencapsulation trials was the one obtained from the pod powder using $375 \mathrm{~W}$ during
10 minutes since it showed the best performance in terms of antioxidant activity.

\subsection{Incorporation of free and microencapsulated hydroalcoholic extracts in yogurts}

The evaluation of the antioxidant activity, through DPPH scavenging activity assay and reducing power (RP), in the control and in yogurts functionalized with free and microencapsulated extracts led to the results presented in Table 3. The functionalized yogurts gave higher activity than the control sample. Moreover, the extract incorporated in the free form conferred a readily perceived higher antioxidant activity to the yogurts, in comparison with the ones containing the microencapsulated extract. This may be due to the fact that the alginate can prevent the release of all the phenolic compounds into the food matrix, highlighting the protecting role of the microspheres in relation to the antioxidant activity of the extract. This is in agreement with the studies conducted by Igual et al. ${ }^{42}$ and Parthasarathi et al. ${ }^{43}$ with Solanum quitoense L. pulp and Garcinia cowa Roxb. fruit, respectively, which proved that the encapsulation was very effective to provide an effective protection of the bioactives. Nevertheless, López-Córdoba et $a l .{ }^{44}$ and Chan et al. ${ }^{45}$ showed that encapsulation of crude extracts of Ilex paraguariensis A. St. Hil. aerial parts and Piper sarmentosum Roxb., respectively, did not affect, positively or negatively, the antioxidant activity of the extracts. Zam et al. ${ }^{46}$ showed that calcium alginate microcapsules could be a good carrier for pomegranate peels' polyphenol and previous 

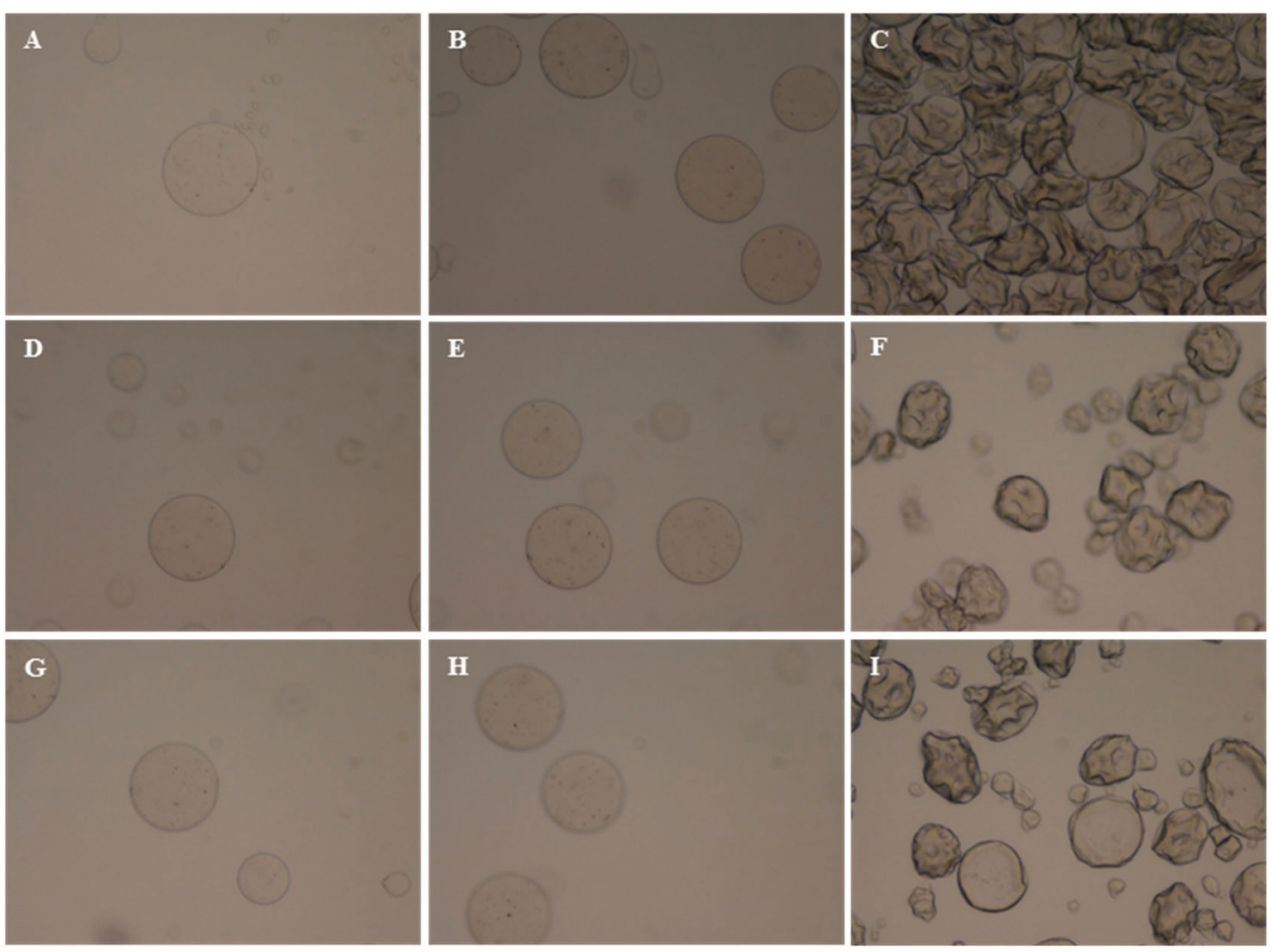

Fig. 2 OM analyses with magnifications of 100x: microspheres after atomization (A, D and G, respectively for 50/400, 75/400 and 100/400 extract/ alginate ratios); microspheres after four hours in contact with a solution of calcium chloride under stirring at $200 \mathrm{rpm}(\mathrm{B}, \mathrm{E}$ and $\mathrm{H}, \mathrm{respectively}$ for 50/400, 75/400 and 100/400 extract/alginate ratios); freeze-dried microspheres (C, F and I, respectively for 50/400, 75/400 and 100/400 extract/ alginate ratios).

Table 3 Antioxidant activity of the yogurts enriched with Ceratonia siliqua free and microencapsulated hydroethanolic extracts (mean \pm SD)

\begin{tabular}{|c|c|c|c|c|c|c|}
\hline \multicolumn{7}{|c|}{0 days } \\
\hline DPPH assay $\left(\mathrm{EC}_{50}, \mathrm{mg} \mathrm{mL}^{-1}\right)$ & $93 \pm 1 \mathrm{a}$ & $59 \pm 5 c$ & $79 \pm 2 b$ & $81 \pm 1 \mathrm{a}$ & $32 \pm 2 c$ & $75 \pm 2 b$ \\
\hline $\mathrm{RP}\left(\mathrm{EC}_{50}, \mathrm{mg} \mathrm{mL}^{-1}\right)$ & $39.4 \pm 0.5 \mathrm{a}$ & $14.8 \pm 0.3 c$ & $36 \pm 3 b$ & $33.6 \pm 0.8 \mathrm{a}$ & $10.89 \pm 0.06 c$ & $29.8 \pm 0.3 b$ \\
\hline
\end{tabular}

DPPH: 2,2-dipheny-1-picrylhydrazyl scavenging activity; RP: reducing power assay. In each line, and for each storage period, different letters mean statistical significant differences $(p<0.05)$.

Table 4 Nutritional value of the yogurt samples along shelf-life storage at $4{ }^{\circ} \mathrm{C}(\mathrm{mean} \pm \mathrm{SD})$

\begin{tabular}{|c|c|c|c|c|c|c|}
\hline \multirow[b]{2}{*}{$\begin{array}{l}\text { Storage days } \\
\text { Samples }\end{array}$} & \multicolumn{3}{|l|}{0 days } & \multicolumn{3}{|l|}{3 days } \\
\hline & $\begin{array}{l}\text { Control } \\
\text { yogurts }\end{array}$ & $\begin{array}{l}\text { Yogurts with } \\
\text { free extract }\end{array}$ & $\begin{array}{l}\text { Yogurts with } \\
\text { microencapsulated extract }\end{array}$ & $\begin{array}{l}\text { Control } \\
\text { yogurts }\end{array}$ & $\begin{array}{l}\text { Yogurts with } \\
\text { free extract }\end{array}$ & $\begin{array}{l}\text { Yogurts with } \\
\text { microencapsulated extract }\end{array}$ \\
\hline Moisture (g/100 g) & $81 \pm 1 a$ & $80 \pm 1 a$ & $80 \pm 2 a$ & $82 \pm 1 a$ & $81 \pm 3 a$ & $81 \pm 1 \mathrm{a}$ \\
\hline Protein $(\mathrm{g} / 100 \mathrm{~g})$ & $4.89 \pm 0.01 b$ & $5.1 \pm 0.1 \mathrm{a}$ & $5.1 \pm 0.1 \mathrm{a}$ & $4.92 \pm 0.03 a$ & $4.9 \pm 0.1 \mathrm{a}$ & $4.95 \pm 0.03 a$ \\
\hline $\operatorname{Ash}(g / 100 \mathrm{~g})$ & $0.53 \pm 0.03 a$ & $0.58 \pm 0.05 a$ & $0.58 \pm 0.01 \mathrm{a}$ & $0.52 \pm 0.01 \mathrm{a}$ & $0.54 \pm 0.01 \mathrm{a}$ & $0.54 \pm 0.02 \mathrm{a}$ \\
\hline Fat $(\mathrm{g} / 100 \mathrm{~g})$ & $2.3 \pm 0.2 \mathrm{a}$ & $2.4 \pm 0.2 \mathrm{a}$ & $2.4 \pm 0.1 \mathrm{a}$ & $2.32 \pm 0.07 a$ & $2.30 \pm 0.06 a$ & $2.34 \pm 0.08 \mathrm{a}$ \\
\hline Carbohydrates $(\mathrm{g} / 100 \mathrm{~g})$ & $11.14 \pm 0.08 b$ & $11.88 \pm 0.06 \mathrm{a}$ & $11.7 \pm 0.1 \mathrm{a}$ & $10.74 \pm 0.08 b$ & $11.2 \pm 0.1 \mathrm{a}$ & $10.9 \pm 0.1 b$ \\
\hline Energy (kcal/100 g) & $84.8 \pm 0.6 b$ & $89.1 \pm 0.5 \mathrm{a}$ & $88.6 \pm 0.9 \mathrm{a}$ & $83.5 \pm 0.2 c$ & $85.0 \pm 0.2 \mathrm{a}$ & $84.4 \pm 0.2 b$ \\
\hline
\end{tabular}

In each line, and for each storage period, different letters mean statistical significant differences $(p<0.05)$. 
studies of our group also corroborated the protective effect of alginate as encapsulation material of natural extracts. ${ }^{4,16}$

The incorporation of the hydroethanolic extracts (free or microencapsulated) did not significantly alter the nutritional value of the yogurts in comparison with the control (non-functionalized samples) (Table 4), with a few exceptions, although considering the natural variation in food matrices analysis, such slight differences can be disregarded. These observations are in accordance with previous studies dealing with different extracts, encapsulating materials and dairy products. ${ }^{16,19}$

\section{Conclusions}

Overall, the performed study successfully implemented the extraction conditions with the application of an ultrasound system to obtain added-value molecules (antioxidants) from a carob by-product (kibbles), namely phenolic compounds with a preponderance of gallotannins. The obtained extracts exhibited significant antioxidant activity at all the different extraction conditions assayed, although the best results were observed using $375 \mathrm{~W}$ and $10 \mathrm{~min}$.

Despite its nutritional characteristics and the importance in human diet, yogurt, which is one of the most consumed fermented dairy products, is not a source of phenolic compounds. The incorporation of suitable extracts, such as the ones of carob kibble, can overcome this fact and improve effectively the antioxidant potential of yogurts, with preserved functional value along shelf-life if microencapsulation is used. The results obtained in this study support not only the potential of carob pod as a viable functional ingredient for the food industry, including the dairy sector, but also the effectiveness of microencapsulation in protecting bioactive components, thus preserving their stability during processing and storage and preventing undesirable interactions with food matrix.

\section{Acknowledgements}

The authors acknowledge FCT (Portugal) for financial support to CIMO (PEst-OE/AGUI0690/2014) and L. Barros (SFRH/BPD/ 107855/2015) research grants, to FCT/MEC and FEDER under Programme PT2020 for financial support to LSRE (Project UID/EQU/50020/2013), and to QREN, ON2 and FEDER (Projects NORTE-07-0124-FEDER-000014 and NORTE-07-0162FEDER-000050).

\section{References}

1 J. Smith and E. Charter, Functional food product development: microencapsulation in functional food product development, A John Wiley \& Sons, Ltd, 2010.

2 C. Hargreaves, NutraCos, 2006, 5, 29-30.

3 C. P. Champagne and P. Fustier, Curr. Opin. Biotechnol., 2007, 18, 184-190.
4 M. I. Dias, I. C. F. R. Ferreira and M. F. Barreiro, Food Funct., 2015, 6, 1035-1052.

5 R. J. Binder, J. E. Coit, K. T. Williams and J. E. Brekke, Food Technol., 1958, 12, 213-216.

6 R. W. Owen, R. Haubner, W. E. Hull, G. Erben, B. Spiegelhalder, H. Bartsh and B. Haber, Food Chem. Toxicol., 2003, 41, 1727-1738.

7 W. F. Collins, Am. Dairy Rev., 1978, 40, 34-35.

8 L. Bravo, N. Grados and F. Saura-Calixto, J. Sci. Food Agric., 1994, 65, 303-306.

9 D. P. Makris and P. Kefalas, Food Technol. Biotechnol., 2004, 42, 105-108.

10 USDA (United States Department of Agriculture), Agricultural Research Service. National nutrient database, NDB no. 16055. [WWW document]. URL http://www.nal.usda. gov/fnic/foodcomp/search/. 7 October 2006.

11 E. M. Rakib, H. Chicha, S. Abouricha, M. Alaoui, A. A. Bouli, M. Hansali and R. W. Owen, J. Nat. Prod., 2010, 3, 134-140.

12 A. Abdul Karim and A. Azlan, Molecules, 2012, 17, 1193111946.

13 L. B. Roseiro, L. C. Duarte, D. L. Oliveira, R. Roque, M. G. Bernardo-Gil, A. I. Martins, C. Sepúlveda, J. Almeida, M. Meireles, F. M. Gírio and A. P. Rauter, Ind. Crops Prod., 2013, 47, 132-138.

14 A. Munin and F. Edwards-Lévy, Pharmaceutics, 2011, 3, 793-829.

15 L. Emberger, Rec. Trav. Lab. Bot. Géol. Fac. Se, 1955, 7, 3-43. 16 A. Martins, L. Barros, A. M. Carvalho, C. Santos-Buelga, I. P. Fernandes, M. F. Barreiro and I. C. F. R. Ferreira, Food Funct., 2014, 5, 1091-1100.

17 V. L. Singleton and J. A. Rossi Jr., Am. J. Enol. Vitic., 1965, 16, 144-158.

18 Z. Jia, M. Tang and J. Wu, Food Chem., 1999, 64, 555-559.

19 C. Caleja, L. Barros, A. L. Antonio, A. Ciric, J. C. M. Barreira, M. Sokovic, M. B. P. P. Oliveira, C. SantosBuelga and I. C. F. R. Ferreira, J. Funct. Food, 2015, 16, 114124.

20 K. Dimitrov, K. Kriaa, B. Hadrich, N. Kechaou and I. Nikov, Kinetics of ultrasound assisted extraction of polyphenols from vegetal sources, XXVth ARS Separatoria, 2010.

21 F. A. Ayaz, H. Torun, S. Ayaz, P. J. Correia, M. Alaiz, C. Sanz, J. Grúz and M. Strnad, J. Food Qual., 2007, 30, 1040-1055.

22 J. M. Hwang, J. S. Cho, T. H. Kim and Y. I. Lee, Biomed. Pharmacother., 2009, 64, 264-270.

23 A. Gonzalez-Sarrias, M. Larrosa, F. A. Tomás-Barberán, P. Dolara and J. C. Espin, Br. J. Nutr., 2010, 104, 503-512.

24 M. C. Lin and M. C. Yin, Cardiovasc. Toxicol., 2013, 13, 185-193.

25 N. A. El-Boghdady, Indian J. Biochem. Biophys., 2011, 48, 380-387.

26 M. U. Rehman, M. Tahir, F. Ali, W. Qamar, A. Lateef, R. Khan, A. Quaiyoom, O.-O. Hamiza and S. Sultana, Mol. Cell. Biochem., 2012, 365, 119-127.

27 M. Sanz, E. Cadahía, E. Esteruelas, A. M. Umñoz, B. F. De Simón, T. Hernández and I. Estrella, J. Agric. Food Chem., 2010, 58, 9631-9640. 
28 M. Papagiannopoulos, H. R. Wollseifen, A. Mellenthin, B. Haber and R. Galensa, J. Agric. Food Chem., 2004, 52(12), 3784-3791.

29 C. M. Yang, H. W. Cheng, T. C. Lin, L. C. Chiang and C. C. Lin, J. Ethnopharmacol., 2007, 110, 555-558.

30 F. L. Hsu, W. J. Huang, T. H. Wu, M. H. Lee, L. C. Chen, H. J. Lu, W. C. Hou and M. H. Lin, Int. J. Mol. Sci., 2012, 13, 6073-6088.

31 D. G. Kang, M. K. Moon, D. H. Choi, J. K. Lee, T. O. Kwon and H. S. Lee, Eur. J. Pharmacol., 2005, 524, 111-119.

32 C. G. Mohan, G. L. Viswanatha, G. Savinay, C. E. Rajendra and P. D. Halemani, Phytomedicine, 2013, 20, 417-426.

33 Y. Chai, H. J. Lee, A. A. Shaik, K. Nkhata, C. Xing, J. Zhang, S. J. Jeong, S. H. Kim and J. Lü, J. Breast Cancer Res., 2010, 12, R67.

34 S. Sancheti, S. Sancheti, B. H. Um and S. Y. Seo, S. Afr. J. Bot., 2010, 76, 285-288.

35 R. Wang, M. Lechtenberg, J. Sendker, F. Petereit, A. Deters and A. Hensel, Fitoterapia, 2013, 84, 308-317.

36 Y. Li and Y. Ding, Food Sci. Human Welln., 2012, 1, 19-25.

37 A. Gohar, S. R. Gedara and H. N. Baraka, J. Med. Plants Res., 2009, 3, 424-428.
38 N. Ortega, A. Maciá, M.-P. Romero, E. Trullols, J.-R. Morello, N. Anglés and M.-J. Motilva, J. Agric. Food Chem., 2009, 57, 7239-7244.

39 F. C. Y. Nishimura, A. C. De Almeida, B. A. Ratti, T. Ueda-Nakamura, C. V. Nakamura, V. F. Ximenes, S. O. Silva and E. Bas, BMC Complementary Altern. Med., 2013, 795916.

40 H. Torun, F. A. Ayaz, N. Colak, J. Grúz and M. Strnad, Food Nutr. Sci., 2013, 4, 547-553.

41 D. McClements, Adv. Colloid Interface Sci., 2012, 174, 1-30.

42 M. Igual, S. Ramires, L. H. Mosquera and N. MartínezNavarrete, Powder Technol., 2014, 256, 233-238.

43 S. Parthasarathi, P. N. Ezhilarasi, B. S. Jena and C. Anandharamakrishnan, Food Bioprod. Process., 2013, 91, 103-110.

44 A. López-Córdoba, L. Deladino, L. Agudelo-Mesa and M. J. Martino, Food Eng., 2014, 124, 158-165.

45 E. Chan, Z. Yim, S. Phan, R. F. Mansa and P. Ravindra, Food Bioprod. Process., 2010, 88, 195-201.

46 W. Zam, G. Bashour, W. Abdelwahed and W. Khayata, Braz. J. Pharm. Sci., 2014, 5, 741-748. 